\title{
Falcotentorial meningiomas: clinical, neuroimaging, and surgical features in six patients
}

\author{
Alfredo Quinones-Hinojosa, M.D., Edward F. Chang, B.S., \\ AND Michael W. MCDERMOTT, M.D. \\ Department of Neurological Surgery, The Brain Tumor Research Center, University of California at \\ San Francisco, California
}

\begin{abstract}
Object. Meningiomas arising from the falcotentorial junction are rare. As a result, their clinical presentation and surgical management are not well described. During the past 3 years, the authors have treated six patients with falcotentorial meningiomas.

Methods. Most patients presented with symptoms related to raised intracranial pressure, including headaches, papilledema, and visual and gait disturbances. Magnetic resonance imaging revealed a smooth, oval, or round mass, which was typically homogeneously enhancing. Angiography was useful in evaluating arterial supply for embolization, when possible, and determining the status of venous collateral supply and sinus patency. The authors detail the surgical technique used in all six patients. Postoperatively, patients experienced transient cortical blindness, which in all cases spontaneously resolved during the course of several days to weeks. They provide a comprehensive description of the presentation and surgical management of falcotentorial meningiomas.

Conclusions. An excellent outcome can be expected when surgery is predicated on detailed preoperative neuroimaging and knowledge of the nuances of the surgical technique.
\end{abstract}

\author{
KEY WORDS • meningioma - surgery • outcome • neurological deficit • \\ radiographic feature
}

Meningiomas arising from the falcotentorial junction are extremely rare. Fewer than 50 cases have been reported in the literature ${ }^{1,-3,9,11-21,26,28-31}$ Because the tumor arises at the junction of dural folds in which the straight sinus and both torcular and arachnoid granulations are found, however, its infrequency in that region is not surprising.

Most patients present with symptoms of increased ICP and occasionally with visual symptoms related to the tumor's occipital location. Because bilateral occipital retraction is required during the operation, transient cortical blindness routinely develops in cases involving largersized tumors. Patients should be informed of this transient neurological deficit prior to surgery.

Because these tumors grow slowly, collateral venous outflow channels for the deep venous system develop via the basal vein of Rosenthal, the petrosal, the precentral cerebellar, and the pontomedullary veins. Preoperative cerebral angiography is crucial to determine the status of the straight sinus because the lower falx cerebri, lateral tentorium, and upper falx cerebelli are excised with the tumor.

We have successfully resected six large meningiomas arising from the falcotentorial junction. We report the clin-

Abbreviations used in this paper: ECA = external carotid artery; ICA = internal carotid artery; ICP = intracranial pressure; MR = magnetic resonance; $\mathrm{PCA}=$ posterior cerebral artery; $\mathrm{SCA}=$ superior cerebellar artery; $\mathrm{VA}=$ vertebral artery. ical, neuroimaging, intraoperative, and postoperative features obtained in six patients with falcotentorial junction meningiomas as well as a review of the literature.

\section{CLINICAL MATERIAL AND METHODS}

\section{Patient Population}

During the course of 3 years, we performed surgery in six patients with meningiomas arising from the falcotentorial junction (Figs. 1 and 2). Four were women and two were men, with a mean age of 42.5 years (range 38-48 years). The origin of tumor was confirmed intraoperatively in all patients, and diagnosis was established by histopathological examination.

\section{Neuroimaging Studies}

Lesions in all patients were evaluated using MR imaging and cerebral angiography. Patients underwent $\mathrm{T}_{1}-$ weighted, $\mathrm{T}_{2}$-weighted, and Gd-enhanced MR imaging. Cerebral angiography included injection of the left subclavian artery, bilateral ICAs, ECÄs, and VAs.

\section{Operative Approach: "Surgeon's Perspective"}

Patient Positioning, Intubation, and CSF Diversion. Because most of these tumors are quite large at the time of diagnosis, preoperative angiography, embolization, and 


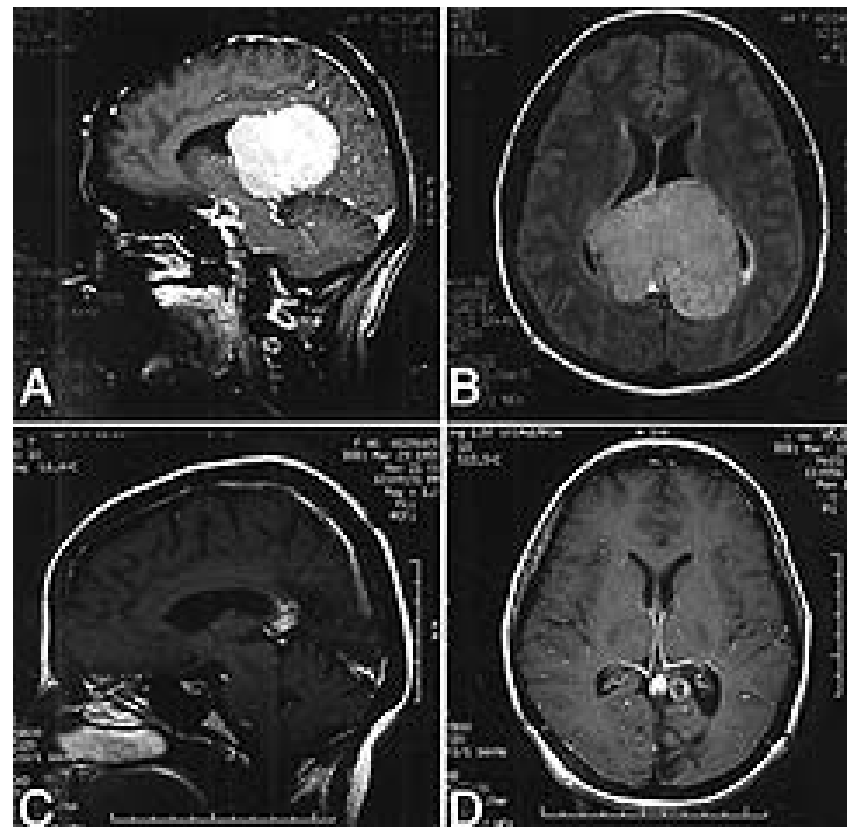

Fig. 1. Representative MR images obtained in a 44-year-old woman who presented with progressive cognitive impairments and personality changes during a 3-year period, with recent episodes of visual hallucinations and urinary incontinence. Imaging revealed a large $(7 \times 4.9 \times 3.8-\mathrm{cm})$ mass arising from the falcotentorial junction. A: Preoperative sagittal $\mathrm{T}_{1}$-weighted contrast-enhanced image demonstrating homogeneous enhancement. B: Preoperative axial $\mathrm{T}_{1}$-weighted image without contrast revealing slight hypointensity. C and D: Postoperative sagittal (C) and axial (D) $\mathrm{T}_{1}-$ weighted contrast-enhanced images demonstrating a near-total resection and small residual enhancement at the vein of Galen. This patient underwent subsequent radiotherapy.

imaging for surgical navigation systems are required. The choice of patient positioning (prone or semisitting) depends on the surgeon's preference and the patient's body habitus. Most surgeons prefer the prone position because it is safe and has a lower risk of air embolism. Obese patients, however, frequently only receive adequate ventilation in the absence of extreme airway pressures-hence, elevated transmitted venous pressures in the semisitting position. Patients considered for the semisitting position should be evaluated for patent foramen ovale preoperatively.

We prefer the prone position, the neck extended on the chest, and the head flexed on the neck. Armored endotracheal tubes should be used to avoid kinking and obstruction resulting from positioning or as the operation proceeds due to softening of the plastic tube. An external ventricular drain is routinely placed via the parietooccipital trajectory with the aid of the surgical navigation system.

Surgical Approach. A large U-shaped incision, based inferiorly, is marked to allow for a supra- and infratentorial craniotomy. Depending on the amount of the posterior fossa component, the foramen magnum is included in cases of larger tumors. The foramen magnum may be opened at the surgeon's discretion when there is a significant infratentorial tumor component. We believe that this reduces resistance against inferior retraction of the cere-

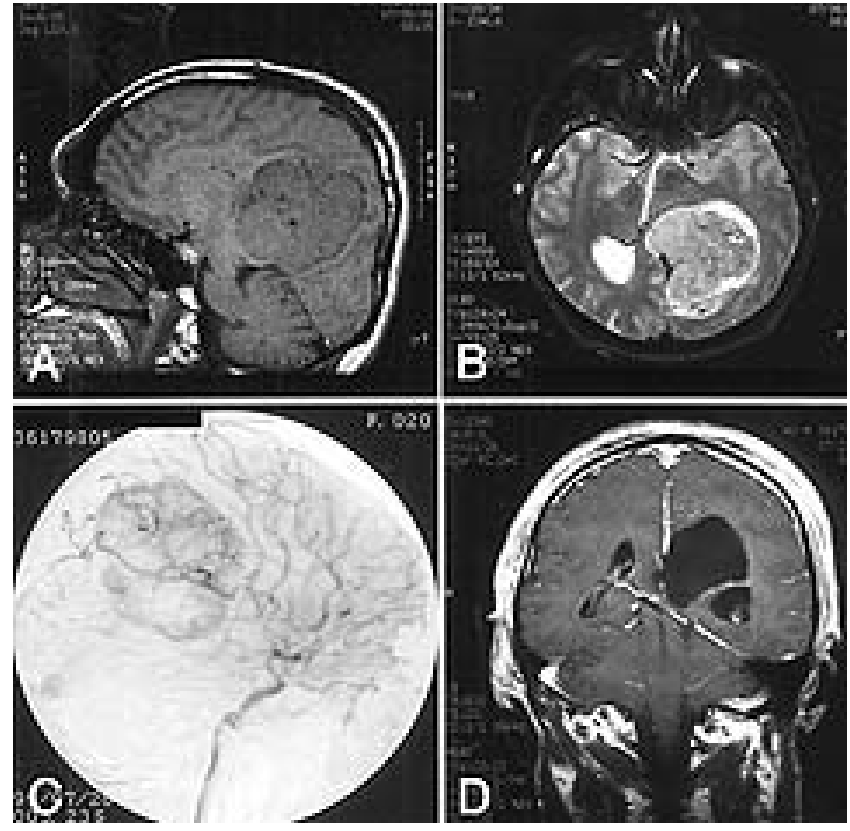

Fig. 2. Representative MR images and angiogram obtained in a 43-year-old man who presented with recent onset of mild cognitive impairment, papilledema, and a right homonymous hemianopsia. Magnetic resonance imaging revealed a $6.9 \times 6.4 \times 5.9-\mathrm{cm}$ mass attached to the falx anteriorly in the region of the falcotentorial junction. A: Preoperative sagittal $\mathrm{T}_{1}$-weighted image demonstrating a large isointense round mass. B: Preoperative axial $\mathrm{T}$-weighted revealing slight hyperintensity. C: Preoperative left VA angiogram demonstrating evidence of hypervascularity, with predominant vascular supply from medial and lateral choroidal arteries off the left PCA. Because the vast extent of blood was supplied by pial arteries, not the ECA, embolization was not attempted. D: Postoperative coronal $\mathrm{T}_{1}$-weighted contrast-enhanced image demonstrating a gross-total resection.

bellar hemispheres necessary for dissection of infratentorial tumor. We take the bone flap off over the torcular and transverse sinuses in two components. First, the supratentorial bone flap is removed and then the dura mater over the torcular and transverse sinuses is dissected under direct vision prior to cutting the infratentorial bone flap.

The dura is opened beyond the lateral margins of the tumor above and below the tentorium. First on one side and then the other, the tentorium is incised from immediately in front of the transverse sinus to its free edge anteriorly at the hiatus. This will eliminate arterial supply via the tentorial arteries, which cannot usually be embolized preoperatively. Next, depending on the angiography-documented status of the torcular and transverse sinuses, either the tentorium is incised from lateral to medial in front of the torcular (patent torcular and one or both transverse sinuses) or the sinuses are ligated using suture at the lateral margin of the tumor and the posterior fossa dura is opened (occluded torcular and transverse sinuses). Finally, the falx cerebri over the top of the tumor is incised as far as is practical, and usually the final incision through the free edge anteriorly can only be made with tumor debulking. This step completes the initial circumferential dural incisions around the tumor, with the falx cerebelli incised after more extensive tumor debulking superiorly. 
TABLE 1

Demographic and clinical data at presentation*

\begin{tabular}{|c|c|c|c|c|}
\hline $\begin{array}{l}\text { Case } \\
\text { No. }\end{array}$ & $\begin{array}{l}\text { Age (yrs), } \\
\text { Sex }\end{array}$ & Symptom & Sign & $\begin{array}{c}\text { Duration of } \\
\text { Symptoms (yrs) }\end{array}$ \\
\hline 1 & $38, \mathrm{~F}$ & headaches, visual disturbances & none & 1 \\
\hline 2 & $44, \mathrm{~F}$ & personality changes, hallucinations, incontinence & none & 3 \\
\hline 3 & $42, \mathrm{~F}$ & headaches & papilledema & 4 \\
\hline 4 & $40, \mathrm{~F}$ & headaches, dizziness & none & 1 \\
\hline 5 & $48, \mathrm{M}$ & headache, diplopia, ataxia, worsened cognition & $\begin{array}{l}\text { CN III w/ ptosis, rt strabismus, slight rt } \\
\text { facial droop }\end{array}$ & 0.5 \\
\hline 6 & 43, M & visual field cut, impaired cognition & papilledema, rt homonymous hemianopsia & 0.2 \\
\hline
\end{tabular}

$* \mathrm{CN}=$ cranial nerve.

Frequently the surgeon will find that because supratentorially the meningioma has grown within the folds of the dura, only the expanded smooth surface of the tentorium and falx is seen. This dura can be incised and the tumor then debulked within the leaves of the dura. The infratentorial aspect of the meningioma is more often the portion separated form the cerebellum by the arachnoid plane, and this can be dissected via either the supra- or infratentorial route. It is helpful to dissect the tumor via both routes as the tumor gets smaller and the surgeon is approaching the last remaining tumor portion near the vein of Galen and deep venous complex. When the last remnant is approached at the anterior falcotentorial junction, care should be taken to identify the vein of Galen. It is safest to use a permanent aneurysm clip to take the vein with a small margin so that the fibrous stump of tumor can be excised behind it. When the remaining tumor stump is approached at the falcotentorial junction, it is difficult to separate from surrounding vascular structures. In cases in which angiography has confirmed the occlusion of the straight sinus, the vein of Galen can be clipped at its junction within the straight sinus in front of the falcotentorial junction. We prefer using permanent aneurysm clips to reduce the chance of tearing the vein. If the straight sinus is patent, which is unusual for larger tumors, a subtotal resection to preserve flow must be accepted.

Because many of these tumors are large and the operations time consuming, we recommend a two-surgeon team. Additionally, the occipital lobes are invariably retracted for hours intermittently and alternately while the resections proceeds, and we cover the pial surface with rubber dams to avoid sticking of cottonoids or telfa that are left on for hours. Each patient and his/her family are informed that postoperative cortical blindness occurs in every case for several days; in our series it has spontaneously resolved in all patients.

In cases of significant cerebral swelling at the conclusion of resection, the bone flap can be left off and the patient positioned safely side to side until the bone can be replaced. In every procedure requiring more than 12 hours, the patient is left intubated overnight and the external ventricular drain used for pressure monitoring and ICP management.

\section{RESULTS}

\section{Patient Characteristics}

At admission, each patient exhibited progressive symptoms and signs of raised ICP. The most common complaints were headache (with or without nausea and vomiting) and visual disturbance. Other complaints included incontinence, personality changes, gait ataxia, dizziness, and mild cognitive impairments. The most common finding on physical examination was papilledema, sometimes accompanied by cranial nerve dysfunction (such as facial droop or homonymous hemianopsia). Patients typically reported progressively worse symptoms for several months before seeking medical attention (mean 29 months; range $0.5-4$ years) (Table 1 ).

\section{Neuroimaging Findings}

Magnetic Resonance Imaging. Magnetic resonance imaging revealed a smooth, round, or oval mass in all patients (Figs. 1 and 2). On $\mathrm{T}_{1}$-weighted images, five tumors were isointense and one was slightly hypointense to brain parenchyma. On $\mathrm{T}_{2}$-weighted images, five lesions were slightly hyperintense and another was isointense. All tu-

TABLE 2

Magnetic resonance imaging findings

\begin{tabular}{clll}
\hline \hline & & \multicolumn{2}{c}{ MR Imaging Sequence } \\
\cline { 2 - 4 } Case No. & $\mathrm{T}_{1}$-Weighted & \multicolumn{1}{c}{$\mathrm{T}_{2}$-Weighted } & Gd Enhancement \\
\hline 1 & isointense & slightly hyperintense & marked, homogeneous \\
2 & isointense & hyperintense & marked, homogeneous \\
3 & isointense & heterogeneous & marked, homogeneous \\
4 & isointense & hyperintense & marked, homogeneous \\
5 & isointense & periventricular hyperintensity & marked, homogeneous \\
6 & isointense & slightly hyperintense & marked, homogeneous \\
\hline
\end{tabular}


A. Quinones-Hinojosa, E. F. Chang, and M. W. McDermott

TABLE 3

Tumor characteristics*

\begin{tabular}{|c|c|c|c|c|}
\hline Case No. & Tumor size $(\mathrm{cm})$ & WHO Grade & Vascular Supply & Venous Occlusion \\
\hline 1 & $6.6 \times 6.6 \times 7$ & I & meningohypophysial trunks (bilat) medial \& lat choroidal vessels & straight sinus \\
\hline 2 & $7 \times 4.9 \times 3.8$ & I & lt $\mathrm{PCA}\left(\mathrm{P}_{2} / \mathrm{P}_{3}\right)$ & straight sinus \\
\hline 3 & $5.5 \times 4 \times 2$ & $\begin{array}{c}\mathrm{I} \\
\text { (recurrent) }\end{array}$ & no evidence of hypervascular mass & $\begin{array}{l}\text { internal cerebral veins, vein of Galen, } \\
\text { straight sinus, 1t transverse sinus }\end{array}$ \\
\hline 4 & $1.9 \times 1.7 \times 2.3$ & I & lt meningohypophysial trunk & vein of Galen \\
\hline 5 & $3.3 \times 3.6 \times 4.8$ & III & $\begin{array}{l}\text { rt ICA (inferolat trunk), branch of lt \& rt occipital arteries, } \\
\text { lt middle meningeal artery }\end{array}$ & straight sinus \\
\hline 6 & $6.9 \times 6.4 \times 5.9$ & II & $\begin{array}{l}\text { pial branches from lt anterior choroidal artery, distal parietal } \\
\text { occipital artery, lateral posterior choroidal artery }\end{array}$ & none \\
\hline
\end{tabular}

$* \mathrm{WHO}=$ World Health Organization.

mors were found to have marked homogeneous enhancement after administration of Gd. Hydrocephalus was present in three patients (Table 2). The mean dimension of the falcotentorial meningiomas was $5.2 \times 4.5 \times 4.3 \mathrm{~cm}$ (anteroposterior $\times$ transverse $\times$ craniocaudal) (Table 3 ).

Cerebral Angiography. The tumors in four patients were fed by the branches of the ICA. Three tumors were fed by choroidal arteries, and two tumors were supplied by branches off the meningohypophysial trunk. One was supplied by the abnormal branching from the PCA. In one patient, no clear hypervascular arterial supply could be detected (Table 3). Tumor stain was observed in four cases and was largely homogeneous during the late arterial phase of the arteriogram (Fig. 2C). When the tumor could be observed, its margins were relatively distinct. In five patients, the straight sinus was occluded. In separate cases, the vein of Galen or the transverse sinus was also occluded. In only one patient was venous sinus occlusion absent.

Although preoperative embolization was considered for each patient, it was only performed successfully in one. This patient underwent partial embolization of the tumor, involving the occipital and middle meningeal arteries. Embolization was not undertaken in most cases because the feeding vessels were either too small or inaccessible.

\section{Operative Results and Long-Term Outcome}

No surgery-related mortality occurred in our series, and all patients' complaints and neurological deficits at the time of admission resolved postoperatively. All patients, however, experienced transient cortical visual deficits. Five patients suffered cortical blindness, either complete or only light perception ability. In one patient a left homonymous hemianopsia occurred. In all cases, these visual deficits resolved almost completely by the time of discharge.

Although the operative time was long (range 13-23 hours) (Table 4), there were no unexpected complications. In half of the cases, a gross-total resection was achieved with complete macroscopic removal of the tumor (Simpson Grade I), ${ }^{25}$ as confirmed by postoperative imaging. In the three cases in which a subtotal resection was performed (Simpson Grade II), the patients subsequently underwent gamma knife surgery (Table 5).

No tumor recurred during a mean follow-up period of 25 months (range 15-36 months). Furthermore, all post- operative visual deficits resolved fully within several months.

\section{DISCUSSION}

We have reported our experience in treating six patients with falcotentorial meningiomas.

The mean age of the patients in our series was 42 years, which closely approximates the mean reported age 44.4 years. ${ }^{6,222}$ for patients with posterior fossa meningiomas. We also found that $66 \%$ (four of six cases) of falcotentorial meningiomas occurred in women, which is also consistent with previous reports regarding meningiomas of all locations. The mean symptom duration before admission was 29 months, which is fairly long but is consistent with the extremely large size of the tumors observed here.

Most patients with falcotentorial meningiomas present with complaints of headache and/or visual deficits. Other common complaints include gait disturbance and cognitive impairment. On physical examination, elevated ICP is often manifested by papilledema (two of six patients in our series) or cranial nerve deficits. These findings are consistent with those summarized previously by Asari, et al. ${ }^{3}$

Overall, the imaging characteristics of falcotentorial meningiomas are similar to those of meningiomas in other locations. On $\mathrm{T}_{1}$-weighted images, they are uniformly isointense with surrounding parenchyma, but with a clear peritumoral rim. On $\mathrm{T}_{2}$-weighted images, falcotentorial meningiomas can range from slightly hypointense to slightly hyperintense. After administration of Gd, there is marked, homogeneous enhancement, with variable dural enhancement.

TABLE 4

Surgical technique

\begin{tabular}{|c|c|c|c|c|}
\hline $\begin{array}{c}\text { Case } \\
\text { No. }\end{array}$ & $\begin{array}{l}\text { Preop } \\
\text { Embo- } \\
\text { lization }\end{array}$ & Op Approach & $\begin{array}{c}\text { Intraop } \\
\text { Navigation }\end{array}$ & $\begin{array}{l}\text { Op Time } \\
(\mathrm{hrs})\end{array}$ \\
\hline 1 & no & torcular (bilat occipitoparietal) & Stealth & 23.5 \\
\hline 2 & no & torcular (bilat occipitoparietal) & Stealth & 22 \\
\hline 3 & no & torcular (bilat occipitoparietal) & Stealth & 16 \\
\hline 4 & no & rt occipital parietal & Stealth & 14 \\
\hline 5 & yes & bilat occipital & ISG & 19 \\
\hline 6 & no & bilat occipital & ISG & 13 \\
\hline
\end{tabular}


TABLE 5

Postoperative and follow-up results

\begin{tabular}{|c|c|c|c|c|c|}
\hline \multirow{2}{*}{$\begin{array}{l}\text { Case } \\
\text { No. }\end{array}$} & \multirow{2}{*}{$\begin{array}{c}\text { Simpson } \\
\text { Resection } \\
\text { Grade }\end{array}$} & \multirow{2}{*}{$\begin{array}{l}\text { Compli- } \\
\text { cation }\end{array}$} & \multicolumn{2}{|c|}{ Examination } & \multirow{2}{*}{$\begin{array}{l}\text { Radio- } \\
\text { surgery }\end{array}$} \\
\hline & & & Immediate Postop & Discharge & \\
\hline 1 & I & none & cortical blindness & $\begin{array}{l}\text { bilat light perception, finger counting, } \\
\text { mild diplopia }\end{array}$ & no \\
\hline 2 & Il & none & cortical blindness (light perception only) & lt: 20/800; rt: 20/800; finger counting & yes \\
\hline 3 & II & none & cortical blindness (light perception only) & rt: 20/400; 1t: 20/200; 1t hemianopsia & yes \\
\hline 4 & II & none & lt homonymous hemianopsia, hallucinations & normal visual fields & yes \\
\hline 5 & I & none & cortical blindness, severe nausea and vomiting & $20 / 30$ bilat & no \\
\hline 6 & I & none & cortical blindness & normal visual fields & no \\
\hline
\end{tabular}

Cerebral angiography reveals that falcotentorial meningiomas usually derive their vascular supply from the ICA, ECA, and/or the PCA. Supply from the ICA included the meningohypophysial branches off the posterior trunk, branches off the inferolateral trunk, and the anterior choroidal artery. The ECA supply came mainly from branch- es of the middle meningeal artery and ophthalmic arteries. Posterior cerebral artery supply was derived from the medial and lateral choroidal arteries. In several cases, angiography of the tumor resulted in clear tumor stain or hypervascular blush seen in the late arterial phase. In a majority of cases reported on in the literature, either the vein of

TABLE 6

Selected literature review: previously reported falcotentorial meningiomas*

\begin{tabular}{|c|c|c|c|c|c|}
\hline Authors \& Year & $\begin{array}{l}\text { Age }(y r s) \\
\text { Sex }\end{array}$ & $\begin{array}{l}\text { Lesion } \\
\text { Size }(\mathrm{cm})\end{array}$ & $\begin{array}{l}\text { Feeding } \\
\text { Arteries (branch) }\end{array}$ & $\begin{array}{l}\text { Venous } \\
\text { Occlusion }\end{array}$ & Op approach \\
\hline Halpert, et al., 1949 & $20, \mathrm{~F}$ & 5 & ND & ND & rt frontal \\
\hline Sachs, et al., 1962 & $50, \mathrm{~F}$ & ND & ND & ND & rt occipital transtentorial \\
\hline Zingesser \& Schecter, 1964 & $45, \mathrm{~F}$ & 5 & ND & ND & rt occipital transtentorial \\
\hline Lazar \& Clark, 1974 & $60, \mathrm{~F}$ & 8 & ND & ND & rt occipital transtentorial \\
\hline \multirow[t]{2}{*}{ Papo \& Salvolini, 1974} & $56, \mathrm{~F}$ & tangerine-sized & tentorial, PICA, \& SCA & ND & rt occipital \& suboccipital \\
\hline & $34, \mathrm{M}$ & plum-sized & occipital & ND & rt occipital transtentorial \\
\hline Carey, et al., 1975 & $57, \mathrm{~F}$ & ND & ND & ND & rt occipital transtentorial \\
\hline Nishiura, et al., 1981 & $49, \mathrm{~F}$ & ND & $\begin{array}{l}\text { posterior choroidal, } \\
\text { medial \& posterior } \\
\text { meningeal }\end{array}$ & vein of Galen, ICV & rt occipital transtentorial \\
\hline Suzuki, et al., 1984 & $59, \mathrm{~F}$ & 4.5 & ND & ND & interhemispheric transtentorial \\
\hline Ohata, 1985 & $50, \mathrm{~F}$ & 4 & tentorial & straight sinus & rt occipital transtentorial \\
\hline Misu, et al., 1987 & $45, \mathrm{~F}$ & ND & $\begin{array}{l}\text { posterior choroidal, } \\
\text { medial \& posterior } \\
\text { meningeal }\end{array}$ & vein of Galen & infratentorial supracerebellar \\
\hline Araga, et al., 1989 & $59, \mathrm{~F}$ & 3 & PCA & ND & bioccipital \\
\hline Toyota, et al., 1990 & $58, \mathrm{M}$ & 2.5 & tentorial & ND & $\begin{array}{l}\text { rt parietooccipital interhemi- } \\
\text { spheric }\end{array}$ \\
\hline Yamazaki, et al., 1991 & $41, \mathrm{~F}$ & 3 & tentorial & ND & bioccipital \\
\hline \multirow[t]{2}{*}{ Odake, 1992} & $47, \mathrm{M}$ & ND & pericallosal & straight sinus & $\begin{array}{l}\text { It parietooccipital interhemi- } \\
\text { spheric }\end{array}$ \\
\hline & $77, \mathrm{~F}$ & ND & ND & straight sinus & $\begin{array}{l}\text { supra- \& infratentorial rt inter- } \\
\text { hemispheric }\end{array}$ \\
\hline \multirow[t]{7}{*}{ Asari, et al., 1994} & $63, \mathrm{~F}$ & 4.6 & tentorial & $\begin{array}{l}\text { straight sinus, vein of } \\
\text { Galen }\end{array}$ & rt occipital transtentorial \\
\hline & $26, \mathrm{M}$ & 5.2 & tentorial & $\begin{array}{l}\text { straight sinus, vein of } \\
\text { Galen }\end{array}$ & rt occipital transtentorial \\
\hline & $38, \mathrm{~F}$ & 4.5 & PCA \& SCA & straight sinus & rt occipital transtentorial \\
\hline & $66, \mathrm{~F}$ & 3.8 & tentorial & patent & rt occipital transtentorial \\
\hline & $62, \mathrm{M}$ & 5 & PCA \& SCA & $\begin{array}{l}\text { straight sinus, vein of } \\
\text { Galen, \& ICV }\end{array}$ & rt occipital transtentorial \\
\hline & $67, \mathrm{~F}$ & 5.6 & tentorial & vein of Galen & rt occipital transtentorial \\
\hline & $30, \mathrm{M}$ & 9.8 & PCA \& SCA & vein of Galen & rt occipital transtentorial \\
\hline Gokalp, et al., 1995† & ND & ND & ND & ND & ND \\
\hline \multirow[t]{4}{*}{ Okami, et al., 2001} & $64, \mathrm{~F}$ & 2.5 & ND & ND & rt occipital transtentorial \\
\hline & $60, \mathrm{~F}$ & 5 & ND & ND & rt occipital transtentorial \\
\hline & $53, \mathrm{~F}$ & 7 & ND & ND & rt occipital transtentorial \\
\hline & $53, \mathrm{~F}$ & 5 & ND & ND & rt occipital transtentorial \\
\hline
\end{tabular}

* ICV = internal cerebral vein; ND = not described; PICA = posterior inferior cerebellar artery.

$\uparrow$ The seven cases in this study were not described individually. 
Galen or the straight sinus is occluded. ${ }^{3}$ Identifying occlusion and the development of the collateral venous channels is extremely important for successful resection of falcotentorial meningiomas. ${ }^{6}$ Although preoperative embolization is a useful adjuvant in the surgical treatment of meningiomas, we found that in only one case was the supplying artery amenable to embolization. Many of the vessels supplying the tumor were either too small or technically inaccessible for safe embolization.

Okami and colleagues ${ }^{18}$ have described the occipital transtentorial and the combined midline occipital-suboccipital approach for falcotentorial meningiomas. Several approaches have been described including occipital transtentorial, infratentorial supracerebellar, ${ }^{10,12,27}$ biparietooccipital craniotomy in the sea lion position, ${ }^{26}$ and a combined supra-/infratentorial-transsinus approach as described by Sekhar and Goel ${ }^{24}$ and Ziyal, et al. ${ }^{32}$ The occipital transtentorial approach allows for good visualization of the internal cerebral veins and the posterior and lateral midbrain, has a low risk of air embolism, and provides a relatively wide exposure of the lesion. We prefer the combined supra-/infratentorial approach because most of these tumors are quite large at presentation. The wide exposure achieved using a torcular craniotomy that extends far laterally reduces compression of the occipital lobes against the dural openings, which is important during prolonged retraction. The availability of exposure above and below the tentorium also provides the surgeon with more intraoperative options and allows one to change the plan of attack when troublesome bleeding occurs. Once the tumor is resected down to a stump attached to the junction of the vein of Galen and straight sinus, we prefer to occlude the former by placing a permanent aneurysm clip before coagulation and cutting.

Overall, we had no surgery-related mortality in this series. The most common postoperative neurological deficit was cortical blindness caused by retraction of the occipital lobe. All patients, however, experienced marked improvement by discharge and full recovery several months later.

\section{CONCLUSIONS}

Meningiomas arising from the falcotentorial junction are quite rare. We describe in detail the clinical and neuroimaging features as well as surgical management of these lesions. We also document the common occurrence of transient postoperative cortical blindness resulting from retraction of the bilateral occipital lobes. Our findings are consistent with contemporary knowledge disseminated in the recent literature. Overall, falcotentorial meningiomas can be safely managed by evaluating thorough neuroimaging studies and obtaining a wide exposure via a combined supra-/infratentorial-torcular craniotomy technique. In cases involving larger tumors, a two-surgeon team is recommended for an efficient tumor removal and has become a standard approach at our institution.

\section{References}

1. Araga S, Fukada M, Kagimoto H, et al: Transient global amne- sia and falcotentorial meningioma - a case report. Jpn J Psychiatry Neurol 43:201-203, 1989

2. Arai T, Irie K, Akiyama M, et al: [A case of falcotentorial meningioma with visual allesthesia.] No To Shinkei 54:255-259, 2002 (Jpn)

3. Asari S, Maeshiro T, Tomita S, et al: Meningiomas arising from the falcotentorial junction. Clinical features, neuroimaging studies, and surgical treatment. J Neurosurg 82:726-738, 1995

4. Asari S, Yabuno N, Ohmoto T: Magnetic resonance characteristics of meningiomas arising from the falcotentorial junction. Comput Med Imaging Graph 18:181-185, 1994

5. Carey JP, Fisher RG, Pelofsky S: Tentorial meningiomas. Surg Neurol 3:41-44, 1975

6. Castellano F, Ruggiero G: Meningiomas of the posterior fossa. Acta Radiol (Suppl) 104:1-164, 1953

7. Gokalp HZ, Arasil E, Erdogan A, et al: Tentorial meningiomas. Neurosurgery 36:46-51, 1995

8. Halpert B, Wilkins H, Lisle AC Jr: Meningioma of the free margin of the cerebellar tentorium. J Neurosurg 6:74-78, 1949

9. Iplikcogu AC: Falcotentorial meningioma. J Neurosurg 85: 737-738, 1996

10. Konovalov AN, Spallone A, Pitzkhelauri DI: Meningioma of the pineal region: a surgical series of 10 cases. J Neurosurg 85:586-590, 1996

11. Lazar ML, Clark K: Direct surgical management of masses in the region of the vein of Galen. Surg Neurol 2:17-21, 1974

12. Matsuda Y, Inagawa T: Surgical removal of pineal region meningioma-three case reports. Neurol Med Chir 35:594-597, 1995

13. Misu N, Hirota T, Tohyama K: [Meningioma of the falco-tentorial junction developing into the pineal region. Report of two cases.] Neurol Med Chir 27:313-318, 1987 (Jpn)

14. Nishiura I, Handa H, Yamashita J, et al: Successful removal of a huge falcotentorial meningioma by use of the laser. Surg Neurol 16:380-385, 1981

15. Odake G: Meningioma of the falcotentorial region: report of two cases and literature review of occlusion of the galenic system. Neurosurgery 30:788-794, 1992

16. Ohata K: [Simultaneous occurrence of a pituitary adenoma and a falcotentorial junction meningioma. Case report.] Neurol Med Chir 25:680-686, 1985 (Jpn)

17. Ohba S, Kurisu K, Arita K, et al: Falcotentorial meningioma accompanied by temporal lobe hematoma. Hiroshima J Med Sci 50:75-77, 2001

18. Okami N, Kawamata T, Hori T, et al: Surgical treatment of falcotentorial meningioma. J Clin Neurosci (Suppl 1) 8:15-18, 2001

19. Papo I, Salvolini U: Meningiomas of the free margin of the tentorium developing in the pineal region. Neuroradiology 7: 237-243, 1974

20. Piatt JH Jr, Campbell GA: Pineal region meningioma: report of two cases and literature review. Neurosurgery 12:369-376, 1983

21. Ramachandran T, Kim RC, Culebras A: Progressive supranuclear palsy and falcotentorial meningioma. Arch Neurol 39:68, 1982

22. Roberti F, Sekhar LN, Kalavakonda C, et al: Posterior fossa meningiomas: surgical experience in 161 cases. Surg Neurol 56: $8-21,2001$

23. Sachs E Jr, Avman N, Fisher RG: Meningiomas of the pineal region and posterior part of 3rd ventricle. J Neurosurg 19: 325-331, 1962

24. Sekhar LN, Goel A: Combined supratentorial and infratentorial approach to large pineal-region meningioma. Surg Neurol 37: 197-201, 1992

25. Simpson D: The recurrence of intracranial meningiomas after surgical treatment. J Neurol Neurosurg Psychiatry 20:22-39, 1957

26. Suzuki M, Sobata E, Hatanaka M, et al: Total removal of a fal- 


\section{Falcotentorial meningiomas}

cotentorial junction meningioma by biparietooccipital craniotomy in the sea lion position: a case report. Neurosurgery 15: 710-714, 1984

27. Tamaki N, Yin D: Therapeutic strategies and surgical results for pineal region tumours. J Clin Neurosci 7:125-128, 2000

28. Toyota A, Takahashi A, Yoshida Y, et al: [Meningioma of pineal region.] No Shinkei Geka 18:745-749, 1990 (Jpn)

29. Yamazaki T, Takahashi S, Ishii K, et al: Meningioma in the pineal region: preoperative diagnosis with CT, MRI, and angiography. Radiat Med 9:22-25, 1991

30. Yan P, Wang S, Zhang H: [Microsurgical treatment for meningioma of falcotentorial junction.] Zhonghua Wai Ke Za Zhi 37:245-247, 1999 (Chn)
31. Zingesser LH, Schecter MM: The radiology of masses lying within and adjacent to the tentorial hiatus. Br J Radiol 37: 486-510, 1964

32. Ziyal IM, Sekhar LN, Salas E, et al: Combined supra/infratentorial-transsinus approach to large pineal region tumors. J Neurosurg 88:1050-1057, 1998

Manuscript received May 9, 2003.

Accepted in final form June 2, 2003.

Address reprint requests to: Alfredo Quinones-Hinojosa, M.D., Department of Neurological Surgery, University of California at San Francisco, 505 Parnassus Avenue, M-779, San Francisco, California 94143-0112. email: quinones@ neurosurg.ucsf.edu. 